\title{
Log - Derived Pressure Profile Modelling in a Niger Delta Field
}

\author{
Engr. Chimaroke Anyanwu \\ Department of Petroleum Engineering, \\ University of Port Harcourt, \\ Nigeria
}

\author{
Prof. Adewale Dosunmu \\ Department of Petroleum Engineering, \\ University of Port Harcourt, \\ Nigeria
}

\begin{abstract}
Failure to accurately determine pore pressures prior to well planning has led to costly drilling failures and major environmental concerns. Uncertainty in these pressures arise from the lack of fit for purpose models suitable for pressures in the Niger Delta. In this work, Log methods have been applied to predict pore pressures for a field in the Niger Delta. RFT data has been used to validate existing pressure modelling methods to aid in selecting best suited model for this field.
\end{abstract}

Keywords- Pore pressure, modelling, Niger Delta, Well Logs

\section{INTRODUCTION}

Accurate prediction of pore pressure of formations is one of the big problems facing drillers in exploration areas today. The pore pressure, together with fracture gradient, determines the mud weight that is needed. Too much mud weight fractures the rock; too little mud weight allows formation fluids to come into the well and can cause blow-outs if not controlled.

Pore Pressure Prediction (PPP) can provide timely warning of the potential for a gas kick so that the driller can adjust mud weight well before a kick is allowed to occur. The consequences of a gas kick are usually very costly delays in the drilling process while steps are taken to equilibrate the pressure in the well. In extreme cases a gas kick can become a blow-out with much more catastrophic consequences up to and including the loss of the well.

Pore pressure prediction also impacts the decision for placement of casing strings. The decision to place casing is determined by the stability of the well at a particular level or levels, and by the perceived risk of encountering a gas kick. In the case of very expensive Deep Water wells, a conservative approach is taken by the driller, in which a more than optimal number of casing strings are placed.

Accurate prediction of pore and fracture pressures enables an oil and gas well project to be drilled in a safe and cost effective manner.This forms the basis for casing setting depth selection. However, the importance cannot be over emphasized as improper prediction can lead to loss of capital expenditure, collateral damage and ultimately poor well design and eventual loss of well integrity. The industry standard stipulates an overbalance of 200 psi (not always) for effective drilling of hole sections. Below this can lead to flow of formation fluids into the wellbore and if not noticed or controlled in time can lead to a blowout. A blow out is an uncontrolled flow of reservoir fluids to surface in most cases gas.

Pore pressure prediction methods applied in the Niger Delta are based on correlations developed in other parts of the world and this generated huge uncertainties in well planning and drilling. No single correlation estimates accurately. There is therefore the need to compare methods as to establish basis for well pressure control.

This work compares existing models with direct pressure measurement to validate them and select best suited one for the field of interest.

\section{THEORITICAL BACKGROUND}

Drilling a well to an anticipated target depth is not satisfactory in the circumstances where the configuration of the well has no utility. In these circumstances, the diameter of the hole must be sufficiently sixed in order to assure that a suitable completion may be accomplished. The well which is producing the formation may be damaged beyond repair. This requisite of well planning may be difficult to attain if the well planning situation incorporates borehole geometry which may be the causal attribute of mud challenges, profound zones and abnormal pressure characteristics (Villaescusa et al. 2002; Araujo et al. 2005; Nelson et al. 2005).

Pore pressure prediction involves quantifying pore pressure from rock property variation in particular changes in sonic velocity or resistivity, Mouchet and Mitchell (1989) and Sayer (2006).

Indeed, the ultimate goal in the development of a pore pressure prediction strategy is to accurately estimate pore pressure from offset well sonic data (i.e. predrilled) Sayer (2006). Most successful pore pressure prediction strategies especially those using sonic log data, are employed in regions where overpressure is generally by disequilibrium compaction Gutierrez et al (2006).

Overpressures generated by disequilibrium compaction are associated with anomalously high sediment porosities (under compaction) and are thus more readily detectable Sayers et al (2002). However, over pressure generated by post depositional fluid expansion mechanisms (e.g., Kerogen-togas maturation) are not associated with a porosity anomaly and thus more difficult to detect and for pore pressure to be quantified Miller et al (2002) and Gutierrez et al (2006). 


\section{PORE PRESSURE PREDICTION STRATEGIES}

Terzaghi (1943) developed a simple relationship between pore pressure and the effective stress of the rock. Even though his relationship was determined empirically, it was proved later that it can be derived analytically from 1-D compaction theory. Terzaghi (1943) determined pore pressure from the effective vertical stress and the overburden stress by the following relationship:

$$
P_{F}=\sigma_{O B}-\sigma_{E V}
$$

Where $P_{F}$ is the pore pressure,

$\sigma_{O B}$ is the overburden stress and

$\sigma_{E V}$ is the effective vertical stress, all with units in $p s i$.

Sayers et al (2002) used Slotnick's relationship as the normally pressured velocity for pore pressure prediction. A normal compaction trend for shale acoustic travel time with depth in the Carnarvon basin was established by fitting an exponential relationship to average acoustic travel times from 17 normally pressured wells.

$$
\Delta T_{n}=225+391 e^{-0.00106 z}
$$

It has been a conventional approach to foretell pore pressure prior to the commencement of drilling activities by means of the traditional seismic stacking speeds with a conventional compaction tendency analysis as is employed by Eaton (1972)

$$
P_{p g}=O B G-\left(O B G-P_{n g}\right)\left(\frac{\Delta t_{n}}{\Delta t}\right)^{3}
$$

where $\Delta \mathrm{tn}$ is the sonic transit time for normally pressured sales obtained by extrapolating normal trends; $\Delta \mathrm{t}$ is actual well $\log$ data.

Zhang $\{2005)$ presented Bowers method for pore pressure prediction as follows

$$
p=\sigma_{V}-\left(\frac{v_{p}-v_{m l}}{A}\right)^{\frac{1}{B}}
$$

Where for Gulf of mexico A ranges from 19 to 20 and B from 0.7 to 0.75 ; vp and vml are compressional and mudline travel velocities in $\mathrm{ft} / \mathrm{sec}$.

In the past few decades, the oil exploration and exploitation organizations which have operated in the Niger Delta have effectively applied the pore pressure forecasting in order to plan cost avoidant aspects and to apply hazard avoidant measures. Notwithstanding, the pressure formations have the aspect of being challenging in their accurate assessment in the presence of the existence of unusual pressures. The technologies which influence pore pressure prediction are experiencing continuous improvement. The aspects of novel computer technologies, new formulas, new seismic prediction paradigms and deep water boring have assertively influenced the aspect of well planning (Chukwuma et al. 2013; Francis 2013).

\section{PRESSURE DETERMINATION FOR NIGER DELTA FIELD}

The poor nature of the data as a result of poor logging practices presented a challenge to its interpretation. However with careful analytical procedures based on field experiences and theoretical background a pore pressure profile was established both by Sonic and resistivity methods.

The shales have been identified and delineated using the gamma ray data by providing a flexible benchmark that gives the shale baseline. Since Gamma ray tracks range between 0 to 150 , a benchmark of 75 was used to delineate the sands and sieve off the data as shale established pore pressures are more reliable. However on plotting this new shale zone resistivity the log showed much noise such that it was difficult to identify a good expected trend for abnormal pressure determination. More so the trend showed a right oriented elbow instead of left as is conventional in resistivity logs (Fig. 1).

To handle this occurrence, further delineation was conducted to identify zones of clean shales by raising the benchmark to 100 gAPI (fig. 2). While this value is not conventional, however based on field experiences a good shale can be identified in this range.

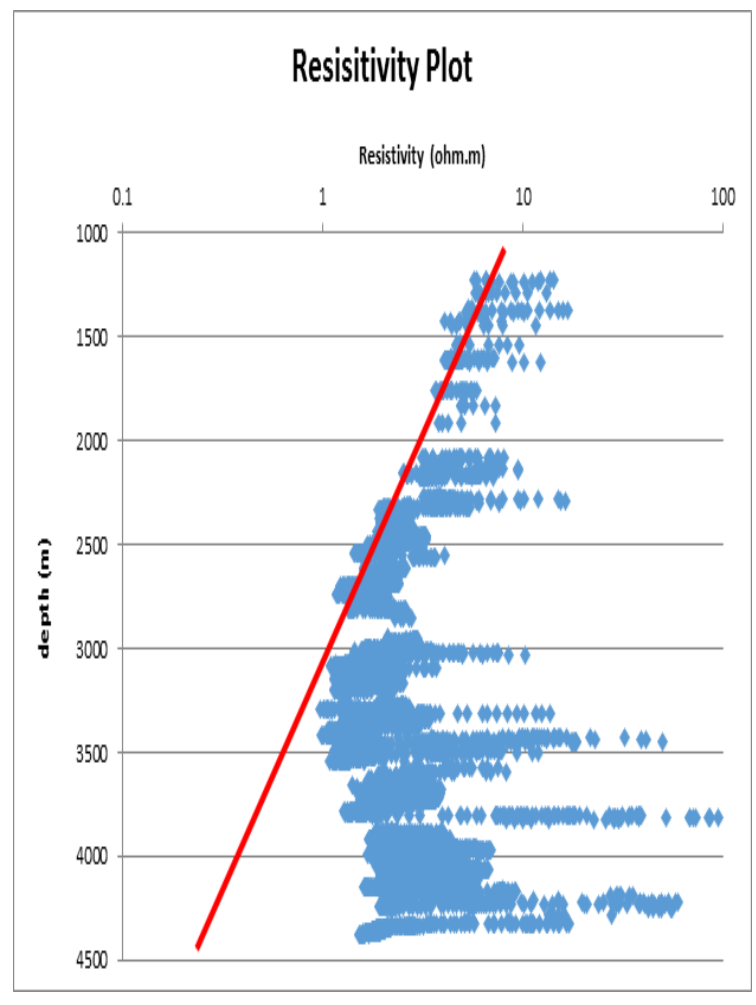

Fig. 1. Resitivity Data for pressure prediction 


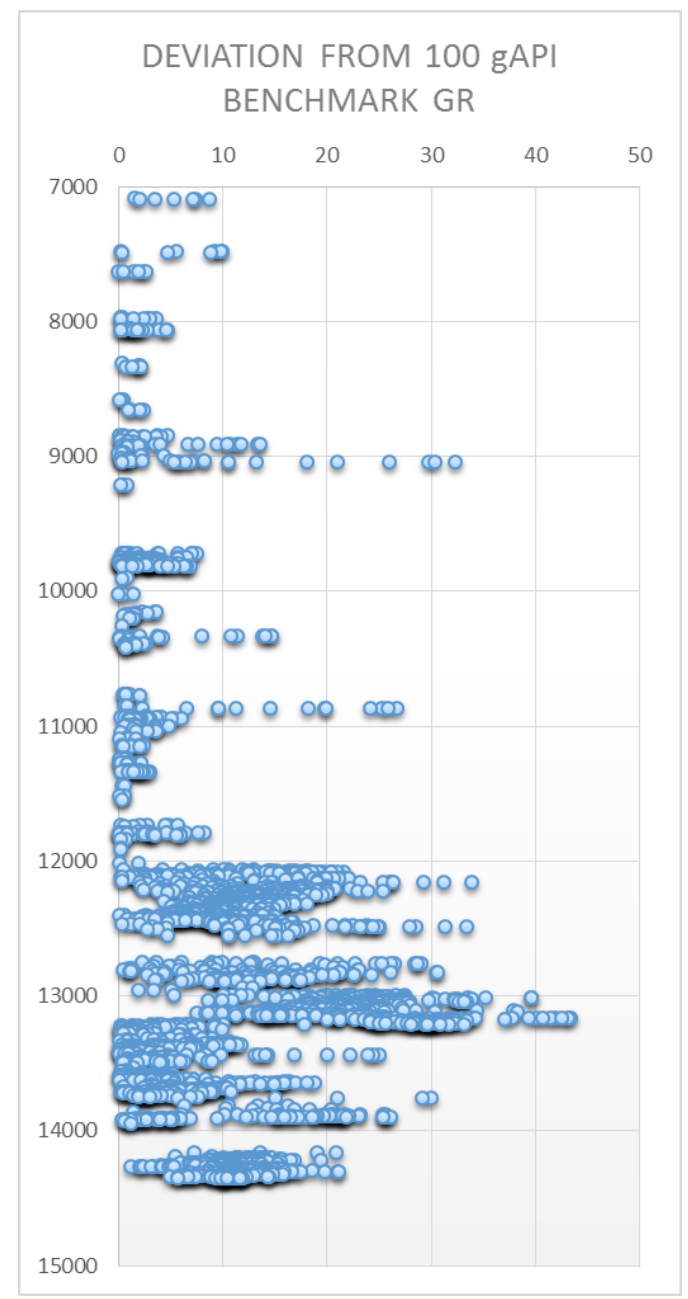

Fig. 2. Gamma Ray Log Benchmark

In the placement of the normal pressure trendline, possible trends were studied carefully as more than 1 spot was identified. The new benchmark has led to removal of more intervals leaving most of the deeper zones as tentative region for placement of trendline. The decision to go this way is established by plotting the spontaneous Potential which is expected to explain the opposite trend of resistivity observed earlier.

The SP showed that these shallow intervals are high salinity zones and as such instead of compaction to be the only contribution to resistivity recorded, the salinity caused and increase in instead of decrease in shale resistivity.

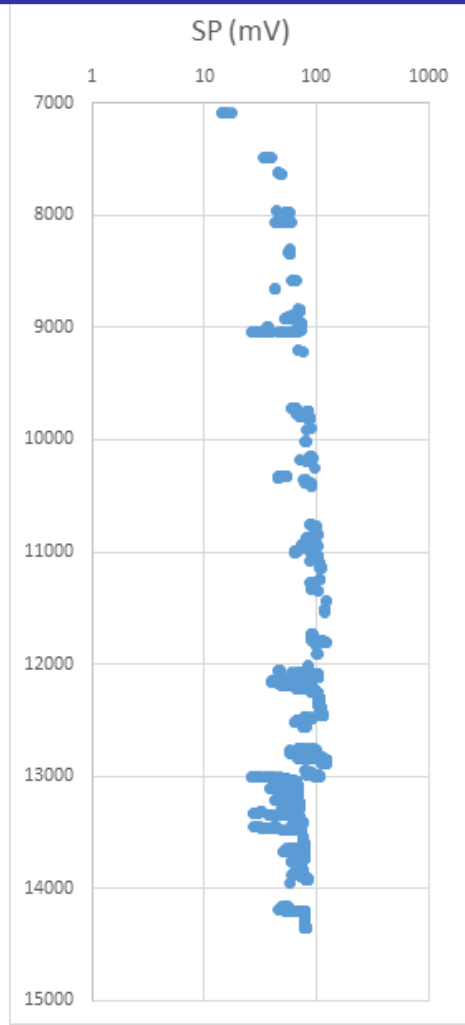

Fig. 3. SP logs showing high salinity zones

Based on this it was concluded that region of cleaner shales where the trendline must be placed is much deeper. Also the fact that some of the data presented here have been truncated and does not reflect a full well measurement to TD, points to the fact that more direct measurement (e.g. MDT, RFT, Kick, etc) is needed to verify what is obtainable. The trend line and the Rshale as well as Rnormal used to obtain the Eatons Pore pressure gradient in psi/ft have been presented here. Also, the sonic data from the set of intervals used in plotting the resistivity logs where maintained in determining the sonic plot as well as the normal trend line. The pressure profiles from both sonic and resistivity methods have been presented here and compared side by side for validation purposes. Since formation water sampling data or saturation data was not available for this work, the water resistivity method was applied to determine water density.

With maximum SP determined the depth corresponding to this zone was identified and required resitivities including Total Resistivity, Rt, Mud Filterate resitvity, Rmf, and temperature conversions and corrrections performed for the depth of interest. Previous temperature logs run on this field show an average of $0.78 \mathrm{DEG} / 100 \mathrm{ft}$ and hence coupled with standard temperatures, the formation temperatures have been determined and presented here as well.

The table below shows a summary of the water density determination calculations. Standard petrophyics charts approved by industry where also used as well to arrive at the values presented. 
TABLE I. WATER GRADIENT DETERMINATION

\begin{tabular}{|c|c|c|c|}
\hline DEPTH INTERVAL, FT & 20 & 14370 & 14390 \\
\hline AVE. SP MAX, mV & 82.01 & & \\
\hline DEPTH @ MAX SP & 14385 & $\mathrm{ft}$ & \\
\hline $\begin{array}{l}\text { AVERGE FORMATION } \\
\text { TEMP @ } 80 \text { DEG/100 FT }\end{array}$ & 0.8 & \multicolumn{2}{|c|}{$\mathrm{deg} / 100 \mathrm{ft}$} \\
\hline RESITIVITY @ MAX SP & 1.7017 & & \\
\hline Rmf @ 239.1 F = & 0.12 & & \\
\hline formation temp $\mathrm{C}$ & 115.1 & $\mathrm{C}$ & \\
\hline formation temp $F$ & 239.1 & $\mathrm{~F}$ & \\
\hline from chart $4 \mathrm{Rmf} / \mathrm{Rw}=$ & 20 & & \\
\hline Rwe $=$ & 0.006 & & \\
\hline Rw from chart using $R w e=$ & 0.011 & & \\
\hline $\begin{array}{l}\text { NACL PPM @ 239.14 F and } \\
\text { 0.011 ohm-m }\end{array}$ & 200,000 & ppm & \\
\hline & 0.99 & $\mathrm{~g} / \mathrm{cc}$ & \\
\hline $\begin{array}{l}\text { normal hydrostatic } \\
\text { GRADIENT = }\end{array}$ & 0.43 & Psi/ft & \\
\hline
\end{tabular}

\section{TABLE II. LOG DERIVED PORE PRESSURES}

\begin{tabular}{|l|l|l|l|l|}
\hline DEPTH & $\begin{array}{l}\text { RES. Pp. } \\
\text { (psi) }\end{array}$ & $\begin{array}{l}\text { DEPTH } \\
\text { ft. }\end{array}$ & $\begin{array}{l}\text { SONIC } \\
\text { Pp. } \\
\text { (psi) }\end{array}$ & $\begin{array}{l}\text { BOWERS } \\
\text { Pp. (psi) }\end{array}$ \\
\hline $\mathbf{1 2 4 3 0}$ & 8329.71 & 12,464 & 7,782 & 9,010 \\
\hline $\mathbf{1 2 8 5 0}$ & 8285.00 & 13,120 & 7,924 & 8,979 \\
\hline $\mathbf{1 3 0 9 9}$ & 8860.78 & 13,418 & 8,200 & 11,027 \\
\hline $\mathbf{1 3 4 2 4}$ & 9255.17 & 13,612 & 8,758 & 11,464 \\
\hline $\mathbf{1 3 6 1 5}$ & 10270.07 & 13,914 & 8,765 & 11,543 \\
\hline $\mathbf{1 3 9 2 0}$ & 10390.75 & 14,347 & 9,225 & 12,801 \\
\hline
\end{tabular}

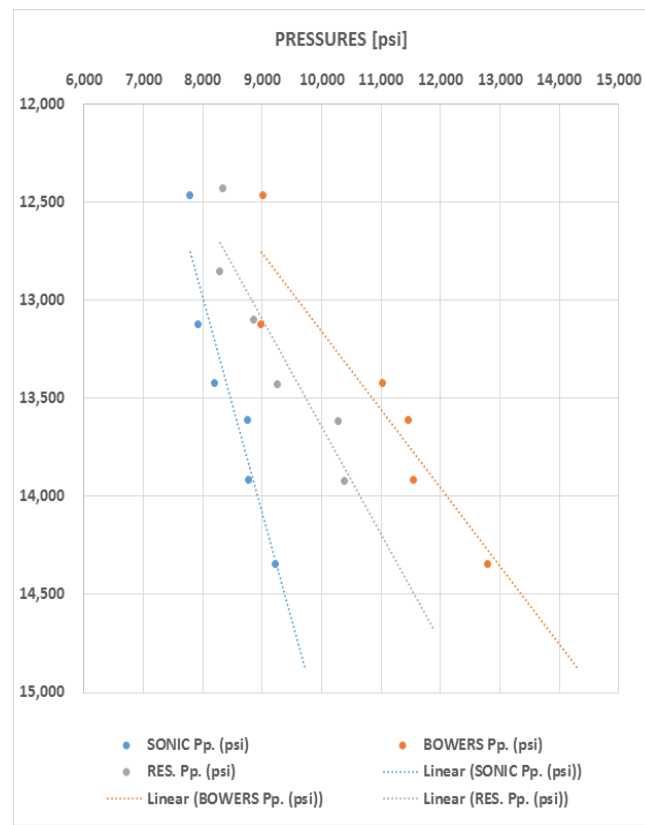

Fig. 4. Derived Pore Pressure Profiles

\section{VALIDATION OF DERIVED PORE PRESSURES}

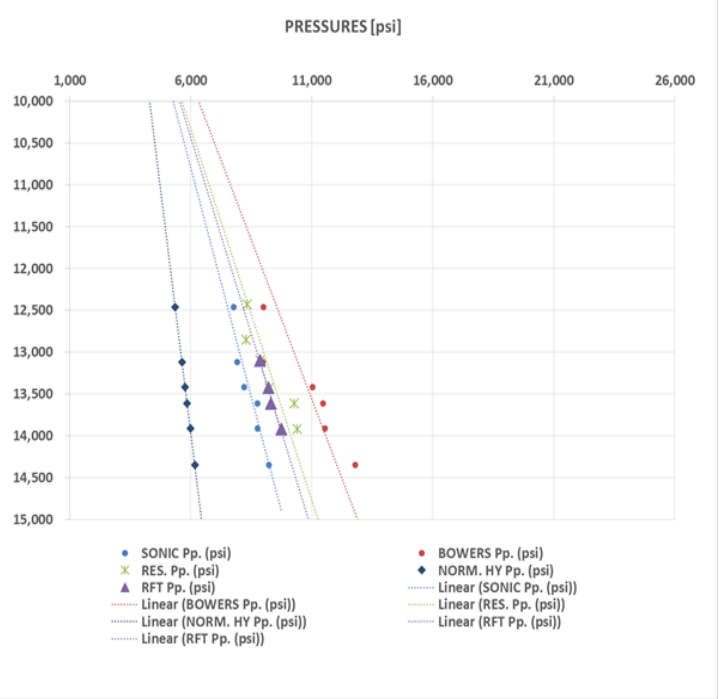

Fig. 5. Validation of Pressures with RFT data

The RFT data presented was measured at the sand face of reservoir sections and extrapolated to identify trends. Pore pressure predictions from resistivity plots show more accurate consistency than others. This could be attributed to the fact the resitivity logs recognize pressure changes due to both change in pore volume as well as chemical changes in formation fluids. 


\section{CONCLUSION}

Bower's and Eaton's method were applied using resistivity and Sonic logs to determine pore pressures in the Niger Delta field. The resistivity derived pore pressures are more consistent with RFT validation data.

The Bowers' method as observed in many parts of the Niger delta fields overestimated pore pressure. This is attributable to poorly consolidated when shallow formations resulting in the velocity in such a formation being very slow.

\section{REFERENCES}

[1] Terzaghi, K., Peck, R.B., Mesri, G., 1996. Soil Mechanics in Engineering Practice (3rd Edition). John Wiley \& Sons.

[2] Eaton, B. A., 1975. The equation for geopressure prediction from well logs. Society of Petroleum Engineers of AIME, paper SPE 5544.
[3] Hottmann, C.E., Johnson, R.K., 1965. Estimation of formation pressures from log-derived shale properties. Paper SPE1110, JPT, 17:717-722

[4] Villaescusa, E, Li, J \& Seti, M (2002), "Stress measurements from oriented core in Australia" Proceeding 5 International Workshop on the Application of Geophysics in Rock Engineering, vol. 72, pp. 1- 7.

[5] Araujo, E, Fontoura, S \& Pastor, JA (2005)."A methodology for drilling through environments with narrow mud weight window (NMWW)", SPE Latin American \& Caribbean Petroleum Engineering Conference, RioDe Janeiro

[6] Nelson, EJ, Meyer, JJ, Hills, RR \& Mildred SD (2005), “Transverse drilling- induced tensile fractures in the West Tuna area, Gippsland Basin, Australia: Implications for insitu stress regime", International Journal of Rock Mechanics and Mining Sciences, vol. 42, no. 3, pp. 361- 371.

[7] Sayers, C.M. (2006). An introduction to velocity based pore pressure estimation.

[8] Mouchet J.P and Mitchell,A. (1989), Abnormal pressure while drilling.

[9] Guitierrez,M.A. Braunsdory N.R and Couzens B.A. (2006). Calibration and ranking of pore pressure prediction models.. 